\title{
Ethical considerations for closing humanitarian projects: a scoping review
}

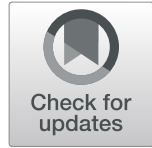

Nicole E. Pal ${ }^{1}$, Lisa Eckenwiler ${ }^{2}$, Shelley-Rose Hyppolite ${ }^{3,4,5}$, John Pringle ${ }^{6}$, Ryoa Chung ${ }^{7}$ and Matthew Hunt ${ }^{1,8^{*}}$ (D)

\section{Background}

The number of people requiring humanitarian assistance has risen steadily in recent years and was estimated to be 201.5 million people in 2017 (ALNAP 2018). The need for assistance is expected to continue rising due to prolonged conflicts, mass population displacement, and increased frequency of natural disasters and climaterelated crises (OCHA 2018). However, funding for humanitarian action has not kept pace with need, and this shortfall continues to grow (ALNAP 2018). These factors contribute to the reality that humanitarian organizations routinely face difficult decisions of where and when to open and close projects. Since humanitarian projects are intended to be temporary interventions responding to the needs of populations affected by crises, project closure is an inescapable component of humanitarian aid. How closure is planned and implemented is a crucial feature of the success of the overall intervention (Gerstenhaber 2014), yet making and enacting decisions to close projects involves complex ethical considerations and reasoning (Hunt and Miao 2018; Lee and Ozerdem 2015; World Food Programme 2004).

Humanitarian projects are closed or transitioned for a variety of reasons, including when program objectives have been met, when the emergency phase has been declared over, and when there is increased insecurity or a lack of funding (Akbarzada and Mackey 2018; Alonso and Brugha 2006; ICRC 2009; Maxwell 1999; Solidarités International 2016; Trócaire 2016). Projects can phase down (reducing services gradually but maintaining a small presence), phase out (tapering services before closing), phase over or hand over (transfer to a local partner), or be abruptly closed (sudden withdrawal without handing over to a local partner) (Gardner et al. 2005; Lee and Ozerdem 2015). Many humanitarian emergency

\footnotetext{
* Correspondence: matthew.hunt@mcgill.ca

${ }^{1}$ School of Physical and Occupational Therapy, McGill University, Montreal, Canada

${ }^{8}$ Centre for Interdisciplinary Research in Rehabilitation, 3654 Sir-William-Osler Boulevard, Montreal, QC H3G 1Y5, Canada

Full list of author information is available at the end of the article
}

projects are transitioned to recovery or longer-term development projects. Closure decisions are also subject to a range of internal and external influences and features related to how humanitarian organizations make decisions more broadly, including diversity in the types and mandates of organizations, the relationships and competition that exists within the aid sector, funding models and organizations' relative dependency on external funding, and institutional structures and cultures that have developed within different organizations (Heyse 2016).

Project closure, and the related idea of "exit strategies", has increasingly been recognized as an important and complex topic in the humanitarian sector since the turn of the twenty-first century (Lee and Ozerdem 2015). The Sphere Handbook underlines the importance of careful planning and implementation of closures, directing humanitarian organizations to "plan a transition or exit strategy in the early stages of the humanitarian programme that ensures longerterm positive effects and reduces the risk of dependency" (Sphere Association 2018). Many agencies and organizations have developed guides and reports covering topics such as when to exit, types of exit strategies, and "best practices" for implementing a project closure (British Red Cross 2015; British Red Cross n.d.; Gardner et al. 2005; Global CCCM Cluster 2014; IFRC 2016; Inter-Agency Standing Committee 2003; World Food Programme 2004; World Health Organization n.d.). Although significant overlap exists amongst the guides, there is variability on what components contribute to an acceptable closure. These variances have contributed to a lack of clarity and cohesion on this topic (Lee and Ozerdem 2015). Clarifying norms, processes, and ethical principles is important as it may help mitigate the negative consequences of poorly planned and implemented project closures (Anderson et al. 2012; Ford and Bedell 2002; Hunt and Miao 2018; Lee and Ozerdem 2015; Slim 2015; Solidarités International 2016).

Although there has been a discussion of ethical issues related to closing humanitarian projects (Fuller 2006; Hunt and Miao 2018; Hurst et al. 2009; Rubenstein 2015), there has yet to be a comprehensive review focusing on ethics and humanitarian project closure. We 
therefore conducted a scoping review to identify how academic and gray literature sources discuss ethical considerations in relation to the closure of humanitarian projects.

\section{Methods}

Scoping reviews are particularly valuable means to synthesize a diverse body of knowledge, including academic and gray literature sources, through describing its extent, range and nature, and identifying gaps (Arksey and O'Malley 2005). This review answers the following question: How does academic and gray literature discuss ethical considerations related to closing humanitarian projects? For the purposes of this review, ethical considerations include aspects of closing projects that are described, implicitly or explicitly, as either consistent with or infringing upon values that the authors of these texts hold to be important. We focused on situations of humanitarian crisis arising from armed conflict, political instability, or natural disaster. We included both situations when a project was closed completely and when the project was handed over to another organization or entity, including transitioning to recovery or development organizations.

Following discussion with a librarian, we searched four databases to identify academic articles: Medline, Global Health, Embase, and PAIS. We used a combination of keywords and $\mathrm{MeSH}$ terms related to project closure and humanitarian aid. Examples of MeSH terms include "disasters", "emergency relief", and "natural disasters", other terms used to complete searches include "relief aid", "disaster aid", "humanitarian", "humanitarian aid", "humanitarian organization", "close", "transition" and "exit." To identify gray literature sources, we used three approaches. We implemented Google Searches using multiple search phrases (e.g., "humanitarian exit strategies") and reviewed the first ten pages for relevant documents. We then reviewed websites of seven leading humanitarian organizations. Finally, we sent requests to seven humanitarian healthcare experts asking them to identify reports related to closing humanitarian projects. In addition to these methods, we collected relevant documents available to the research team and hand searched the reference lists of key documents.

We screened collected documents for inclusion in the full analysis. We departed from scoping review methodology in that only one reviewer screened documents. When the reviewer was uncertain about including a document, she reviewed it with another team member. To be retained, articles had to be written in English or French and publicly available online or accessible through the McGill University Library System. In terms of content, documents had to discuss ethical considerations related to project closure (process of decision- making related to project closure and/or the implementation of project closure) in humanitarian crises. When available, titles and abstracts were first reviewed, followed by full texts. The search was completed over a 3-month period between June 2018 and August 2018. Figure 1 illustrates this process using a modified PRISMA flow diagram (Moher et al. 2009).

Sixty documents were included for extraction. The extraction table included information on document bibliometrics (e.g., title, date, authors), context (e.g., type of crisis, location, organization), and ethical considerations. The coding structure used to identify ethical considerations was developed through an iterative process (Arksey and O'Malley 2005). We selected five articles with extensive discussion of the ethical dimensions of project closure. NP and $\mathrm{MH}$ independently reviewed the articles to inductively identify ethical considerations associated with project closure. They then compared their analyses and created a combined list of seven considerations. This structure was then discussed within the research team and further refined as additional articles were extracted. We presented the review findings to a group of ethics, policy, and humanitarian experts during a feedback meeting on May 24, 2019.

\section{Findings}

Of the 60 documents included for extraction, 27 were academic articles, 24 were agency or interagency reports, and nine were books or book chapters. All were published between 1965 and 2018, with 57 published after 2000. Fortyfour documents were published by or focused on specific organizations, including Médecins Sans Frontières (10), the International Committee of the Red Cross (9), the International Federation of the Red Cross and Red Crescent Societies (4), United Nations (3), and the Inter-Agency Standing Committee (3), amongst others. Fifteen documents specified addressing all humanitarian crises, while nine focused on armed conflicts, seven on natural disasters, and six on projects related to refugees or internally displaced persons. The focus of ten documents was detailed descriptions of specific instances of project closures, while the remainder presented more general discussion or guidance related to project closure, and often included case study examples. For a complete description of document characteristics, see Table 1 . We organized our analysis of ethical considerations around two distinct aspects of the closure process: how decisions are made to close projects and how decisions to close are implemented. The majority of the extracted information discussed the latter component relating to how decisions to close are implemented. We identified three ethical considerations related to how decisions are made to close a project and seven ethical considerations associated with how closures are implemented. The latter set of considerations are listed in Table 2, along with associated supporting rationales and implications. 


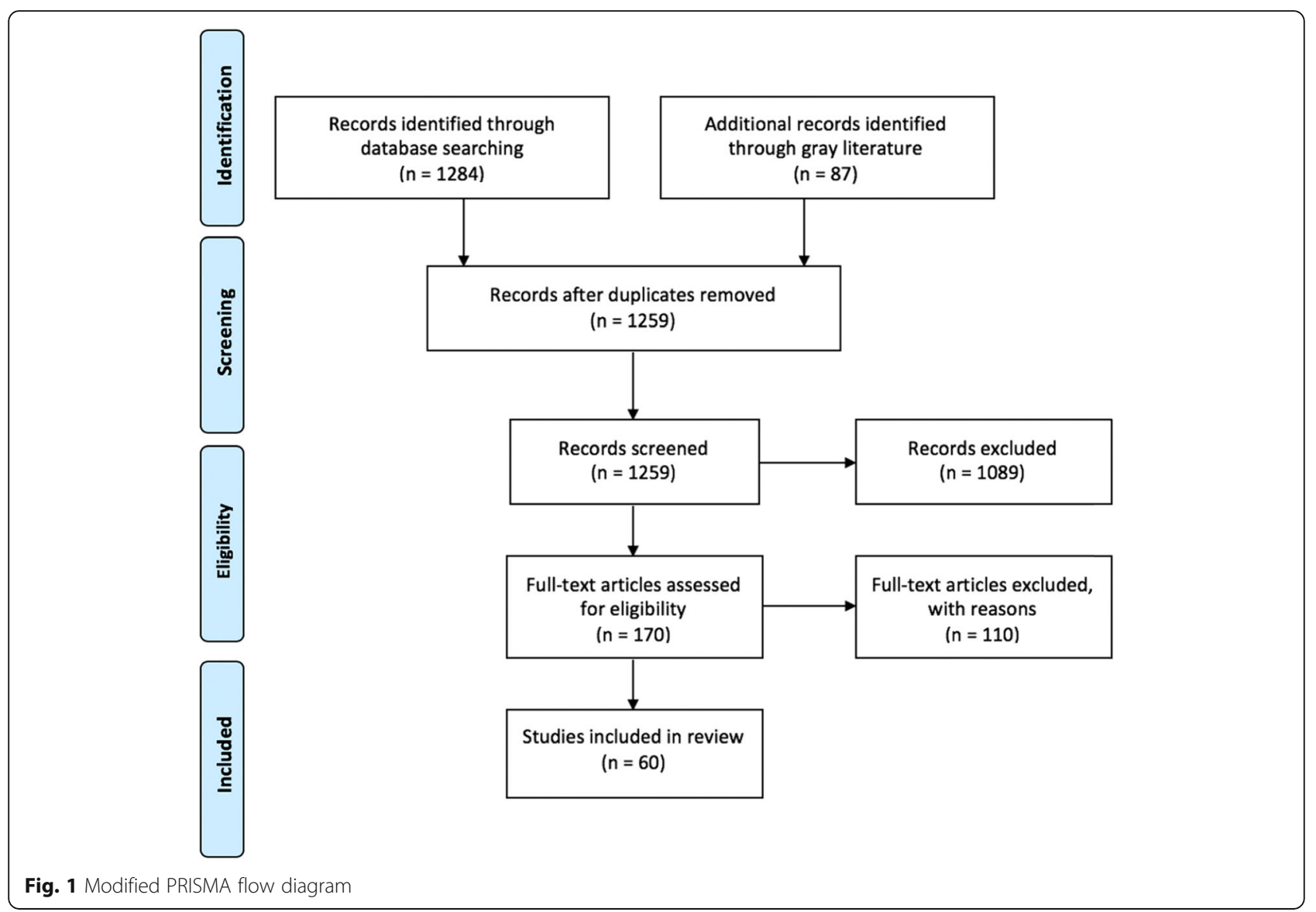

\section{How decisions are made to close projects}

Authors identified a range of ethical considerations relating to the process of deciding to close a project. Most frequently expressed were concerns that decision-making be conducted in ways that include and engage relevant stakeholders, that there is transparency in communication of the process, and that rationales for decisions are well justified and clearly articulated (All In Diary 2011; Anderson et al. 2012; Barnett 2003; Inter-Agency Standing Committee 2003; Rubenstein 2015; Solidarités International 2016; World Food Programme 2004). An emphasis on inclusion in decision-making was reflected by calls to engage with stakeholders involved in the project, such as national staff members, local governments, partner organizations, and communities, so they can provide input and voice concerns (All In Diary 2011; Rubenstein 2015; Solidarités International 2016). The early selection and clear communication of indicators to be used in assessing when to close the project was also advocated, including a World Food Programme report recommending that indicators be established prior to a project's start (World Food Programme 2004), including programmatic indicators (linked to progress towards objectives), contextual indicators (e.g., improvement in humanitarian situation, refugee return), systemic indicators (e.g., government agencies meeting needs of the population), and external indicators (e.g., diminished donor contributions). Several sources highlighted the importance that rationales for decisions be clearly communicated in an effort to minimize feelings of frustration or disappointment (Hunt and Miao 2018; World Food Programme 2004). Sharing information with partners and maintaining thorough records of the decision-making and closure processes are also proposed as important mechanisms to support learning within specific organizations and across the sector (Barnett 2003).

\section{How decisions to close are implemented Responsible planning}

The early development, and periodic reassessment and realignment, of well-designed plans for phasing out or phasing over a project is a key feature of responsible project closure (Aitken et al. 2009; British Red Cross 2015; Gerstenhaber 2014; Inter-Agency Standing Committee 2014). Robust planning for project closure may be overlooked or neglected, however, due to humanitarian organizations' emergency ethos that focuses on present problems, especially where local governments and civil society organizations have limited capacities (Redfield 2013). When planning is lacking, the exit of humanitarian organizations is more likely to be disorganized and lead to disarray with other agencies left 
Table 1 Document characteristics

\begin{tabular}{|c|c|}
\hline Document characteristics & \\
\hline \multicolumn{2}{|l|}{ Source, $n(\%)$} \\
\hline Academic article & $27(45 \%)$ \\
\hline Agency/interagency reports & $24(40 \%)$ \\
\hline Books or book chapters & $9(15 \%)$ \\
\hline Total & $60^{*}$ \\
\hline \multicolumn{2}{|l|}{ Year, $m$} \\
\hline Mode & 2012 \\
\hline Range & $\begin{array}{l}1965- \\
2018\end{array}$ \\
\hline Total & $60^{*}$ \\
\hline \multicolumn{2}{|l|}{ Organizations, n (\%) } \\
\hline None specified & $18(29 \%)$ \\
\hline Médecins Sans Frontières & $10(16 \%)$ \\
\hline The International Committee of the Red Cross & $9(15 \%)$ \\
\hline The International Federation of the Red Cross & $4(6 \%)$ \\
\hline United Nations related & $4(6 \%)$ \\
\hline The Inter-Agency Standing Committee & $3(5 \%)$ \\
\hline Médecins du Monde & $2(3 \%)$ \\
\hline $\begin{array}{l}\text { World Health Organization, OXFAM, CARE, INSEAD } \\
\text { Humanitarian Research Group, C-SAFE, Acting with } \\
\text { Churches, The Global Management Project, The Global } \\
\text { Camp Coordination and Camp Management Cluster, All in } \\
\text { Diary, Solidarités International, Trócaire, Australian Govern- } \\
\text { ment Disaster Management Team }\end{array}$ & $\begin{array}{l}12 \times 1 \\
(19 \%)\end{array}$ \\
\hline Total & $62^{*}$ \\
\hline \multicolumn{2}{|l|}{ Location, n (\%) } \\
\hline Not specified & $42(65 \%)$ \\
\hline Syria & $3(5 \%)$ \\
\hline Palestine & $2(3 \%)$ \\
\hline Iraq & $2(3 \%)$ \\
\hline South Africa & $2(3 \%)$ \\
\hline $\begin{array}{l}\text { South East Asia, East Timor, Uganda, Israel, France, Brazil, } \\
\text { North Ireland, East Africa, Indonesia, Haiti, Myanmar, Libya, } \\
\text { Jordan, Liberia }\end{array}$ & $\begin{array}{l}14 \times 1 \\
(22 \%)\end{array}$ \\
\hline Total & $65^{*}$ \\
\hline \multicolumn{2}{|l|}{ Crisis type, $n$ (\%) } \\
\hline Not specified & $18(28 \%)$ \\
\hline All humanitarian crises & 15 (23\%) \\
\hline Armed conflict & $9(14 \%)$ \\
\hline Natural disasters & $7(11 \%)$ \\
\hline Refugee/IDPs & $6(9 \%)$ \\
\hline Urban violence & $4(6 \%)$ \\
\hline War & $2(3 \%)$ \\
\hline $\begin{array}{l}\text { Violence below threshold of armed conflict, food insecurity, } \\
\text { undocumented migrants and asylum seekers, political } \\
\text { instability }\end{array}$ & $4 \times 1(6 \%)$ \\
\hline Total & $65^{*}$ \\
\hline
\end{tabular}

*Totals greater than 60 indicate one or more documents that specify more than one organization, location, or crisis scrambling to make up the difference (Abramowitz 2015). To avoid such outcomes, planning should be carefully tailored to the context, including funding and partnership parameters, and well thought out early in the project lifecycle (All In Diary 2011; British Red Cross n.d.; Gerstenhaber 2014; Inter-Agency Standing Committee 2014; Lucchi 2012; Solidarités International 2016; World Health Organization n.d.). Some authors advocate for the proactive inclusion of local stakeholders in planning processes in order to enhance relevance for local priorities, avoid or mitigate harms, and promote sustained local impact (British Red Cross n.d.; ICRC 2004). Gerstenhaber suggests that organizations use available guides and tools that have been developed to support robust planning of project closure (Gerstenhaber 2014). As part of the planning cycle, many commentators recommend incorporating post-closure evaluations to monitor impact and to inform planning of future closures (Gardner et al. 2005; Global CCCM Cluster 2014; Hunt and Miao 2018; Seo and Pettigrew 2011; World Health Organization n.d.). A concern related to planning is ensuring the coherence and alignment of steps and timelines that are put in place (Trócaire 2016). These plans should align with commitments that have been made to communities and service recipients (ICRC 2014), as well as with the stated objectives and mandate of the organization (Gerstenhaber 2014).

\section{Collaboration}

Despite numerous identified challenges (Lee and Ozerdem 2015), many authors strongly recommend that humanitarian organizations seek to collaborate with other actors during project closure in order to expand capacity, coordinate services, and increase ownership amongst partners as projects are handed over (Alonso and Brugha 2006; Alpert 2010; Gerstenhaber 2014; Lucchi 2012; World Health Organization n.d.). Ideally, the collaboration model for a phased handover is well integrated into project planning (Lucchi 2012) so that the transition is coordinated with other actors (Alonso and Brugha 2006), with clear and mutually agreed upon roles and responsibilities (Gerstenhaber 2014; Global CCCM Cluster 2014), including with government ministries (Gardner et al. 2005) and development organizations (Inter-Agency Standing Committee 2003; Maxwell 1999). Gerstenhaber reports that the inclusion of other actors promotes ownership of the project as project activities are shifted to those who will be responsible once the NGO leaves, even if doing so is "potentially frustrating and complicated" (Gerstenhaber 2014). For example, challenges may arise related to the harmonization or maintenance of operational standards (Gerstenhaber 2014; Harroff-Tavel 2010). In seeking to promote the participation of representatives of local communities, several authors note that attention should be given to any groups within the population who are experiencing heightened vulnerability or are marginalized (Global CCCM Cluster 2014; Lee 
Table 2 Ethical considerations

\begin{tabular}{ll}
\hline Ethical consideration & Implications \\
\hline Responsible planning & $\begin{array}{l}\text { Promotes greater coherence, continuity, and predictability; can contribute to minimizing } \\
\text { harms and create opportunities to apply lessons learned in other settings. } \\
\text { Collaboration }\end{array}$ \\
$\begin{array}{l}\text { Demonstrates respect for partners and other stakeholders; upholds the dignity and agency } \\
\text { of local communities; can lead to the identification of potential harms. } \\
\text { Enables responsiveness to the particularities of the situation, including where groups are } \\
\text { experiencing increased vulnerability. }\end{array}$ \\
Transparency & $\begin{array}{l}\text { Promotes the agency of stakeholders and demonstrates respect; is a precondition for } \\
\text { accountability by clarifying processes to be followed. } \\
\text { Encompasses vigilance for how closure processes will impact communities, project staff and } \\
\text { pustner organizations, and striving to minimize or avoid harms where possible. }\end{array}$ \\
Fairness & $\begin{array}{l}\text { Promotes the possibility of long-term benefits for local communities, including ongoing access } \\
\text { to quality services. } \\
\text { Attends to concerns of justice in how resources are allocated, as well as how burdens, harms, } \\
\text { and benefits are distributed during and after project closure. }\end{array}$ \\
\hline
\end{tabular}

and Ozerdem 2015). For example, participation from youth and women may be impeded by "male-dominated social structures" or psychological trauma may inhibit involvement (Lee and Ozerdem 2015).

\section{Adaptability}

Plans for project closure require adaptability in the face of the dynamic and evolving contexts of humanitarian crises, including responding to social contexts and ongoing conflicts (Maxwell 1999; Médecins du Monde 2015; World Food Programme 2004). In this sense, those implementing a project closure should avoid rigid thinking in carrying through on planned closure strategies so that they are able to revise their planning as conditions shift, including being responsive to the needs and concerns of groups experiencing increased vulnerability (British Red Cross n.d.; World Food Programme 2004). A flexible approach can be facilitated by ongoing monitoring and needs assessments, including attentiveness to concerns and priorities expressed by local communities (Alonso and Brugha 2006; British Red Cross n.d.; Gardner et al. 2005; World Food Programme 2004). These measures can help to inform aid organizations' decision-making regarding the conditions and timeline for handover to a local partner or other organization, including possibly staggering the transition of different components of the project (Inter-Agency Standing Committee 2003; Maxwell 1999). Adaptability in the approach and sequencing of handover can help to minimize risks of poorly timed or poorly tailored project closures (InterAgency Standing Committee 2003; Maxwell 1999).

\section{Transparency}

Clearly communicating timelines and the steps of project closure with local communities and partners is identified as contributing to a sense of agency for stakeholders, including staff, partners, and community members, in being able to make better informed choices for themselves (IFRC 2016) and feeling greater ownership of the project (Gardner et al. 2005). It also demonstrates respect, promotes dignity, and allows communities to anticipate how the exit will unfold so that they may plan accordingly (Trócaire 2016). It is thus a precondition for enacting accountability. Information should be clearly conveyed to other organizations, for example during cluster meetings, so that they can anticipate any impacts for their own programs (World Health Organization n.d.).

\section{Minimizing harms}

Closing a humanitarian project often has significant consequences for communities that can include broader economic and social effects (Abu-Sada 2012b; Lee and Ozerdem 2015; Redfield 2013; Slim 2015; Solidarités International 2016). These consequences are compounded in situations where communities continue to experience precarity, the project has been comprehensive in scope and long in duration, and there are few or no other entities available to provide the services (Hunt and Miao 2018). Some models of project closure, notably when handover or transition has not been achieved, result in service interruption or cessation. Identifying short- and longer-term risks (Gerstenhaber 2014) and working to avoid or at least minimize harms is thus crucial (Maxwell 1999). This process should include considering whether project closure could exacerbate vulnerabilities or tensions within populations. According to Maxwell, "good analysis of potential harmful impacts, the means to mitigate or prevent these impacts, and a judgement as to whether the harms outweigh the benefits, are all crucial components of program design" (Maxwell 1999). As projects are phased down or out, risks may be mitigated by focusing resources and efforts on the least served areas or those project components that are less robust (World Health Organization n.d.). Delayed closure can also result in harm. Several commentators report that prolonged assistance may 
entrench reliance on outside assistance, thus jeopardizing the goal of a progressive return to autonomy (Lee and Ozerdem 2015; Solidarités International 2016), as well as contributing to inflation that can critically impact local economies (Lee and Ozerdem 2015). Harms may also be experienced by humanitarian workers who feel distress, for example, witnessing a reduction in service quality may "be a heavy burden to bear" (Gerstenhaber 2014), or experienced by organizations, such as reputational damage associated with a poorly managed closure (Abu-Sada 2012b).

\section{Sustainability}

As illustrated by the title of an agency report, continued access to services is an important outcome: "Success is also measured by what you leave behind" (Gerstenhaber 2014). However, many authors describe situations in which organizations ignored or struggled to achieve this goal (Abramowitz 2015; Abu-Sada 2012a; Abu-Sada 2012b; Ashley and Jayousi 2006; Redfield 2013; Rieff 1995). Ashley and Jayousi argue that the positive impacts of humanitarian aid are undermined by a short-term mindset since abrupt exits leave local communities without access to services on which they have come to depend for survival (Ashley and Jayousi 2006). Funding gaps contribute to this situation, including a lack of funding mechanisms bridging relief and development (Maxwell 1999; Patrick 2000). Advocating to donors is thus recommended to convey the importance of supporting partners who will take over project activities (Harroff-Tavel 2010; Maxwell 1999). Efforts to maintain quality of care after a handover are identified as critical and require engagement with governments and other partners (Orach and De Brouwere 2005). In order to incorporate these important aspects of sustainability, diligent planning is required (British Red Cross 2015). A handbook developed by Trócaire argues that "the strongest exit strategies look beyond providing immediate, lifesaving relief services, and look into the future to develop the capacity of partners and affected communities and governments to address the underlying issues and prepare for future crises" (Trócaire 2016). However, a concern identified with capacity building is that it can slow progress toward project closure (British Red Cross n.d.). These discussions of sustainability and capacitybuilding are linked to considerations about the scope of humanitarian action and opportunities to integrate an early recovery approach (Leaning et al. 2011; McGoldrick 2011; UNDP 2012). Those advocating for the adoption of an early recovery approach within a humanitarian response, argue that "just as emergency relief activities are crucial to saving lives by responding to the most urgent human needs, integrating an early recovery approach within humanitarian operations is crucial to the first efforts of a community to recover" ((UNDP 2012).

\section{Fairness}

Several considerations related to distributive justice, including the fair allocation of limited resources, are highlighted in discussions of closure (Gerstenhaber 2014; World Health Organization n.d.). For example, Orach and De Brouwere identify questions about the fair distribution of services between a refugee population and vulnerable long-term residents of a community in the wake of project closure (Orach and De Brouwere 2005). While such concerns are relevant across the project cycle, they raise distinctive considerations as humanitarian organizations work with partners to whom they will hand-over a project. Another source of concern relates to resources expended during and after the closure and whether they should instead be allocated to new projects with more vulnerable communities. For example, Gerstenhaber discusses whether funds should be allocated to evaluate closed projects or if "the money would be better spent in current or future projects" (Gerstenhaber 2014). Issues of sustainability (as discussed above) are also framed in terms of justice and the scope of responsibility for humanitarian organizations towards the communities they are working with and with whom they will work in the future (Leaning et al. 2011).

\section{Discussion}

Closing humanitarian projects is challenging and often ethically fraught. However, it is unavoidable and an inherent component of the cycle of all humanitarian responses. It is also a complex process, involving planning, negotiating, communicating, and adjusting, with multiple decision points. Ethical values are implicated in these steps and may be upheld or challenged by how a closure decision is made and implemented. This review draws attention to how these ethical considerations are discussed in the gray and academic literature. The review illustrates the range of ethical considerations that are implicated in this process and the need for clarification and coherency to support organizations to close projects as ethically as possible within non-ideal circumstances, recognizing the inevitability of compromises and trade-offs (O'Mathúna 2016; Rubenstein 2015).

To our knowledge, this is the first scoping review on the ethics of humanitarian project closure. Our analysis, however, partially maps on to considerations identified for exit strategy principles in the development sector (Lee 2017). These include the importance of early and robust planning, consulting, and communicating with local stakeholders throughout the process, remaining flexible to evolving conditions, and implementing a sustainable approach. Less discussion, however, was drawn to topics of fairness and minimizing risks of harm. The 
distinctive features of humanitarian action, in particular its inherently reactive nature in response to crises and associated temporal challenges, will shape how these concerns are addressed. For example, the planning and design phase is likely to be very compressed in a sudden onset disaster. Differences in reasons for exiting are also apparent, as are contextual features related to risks and the possibility of partnerships. While humanitarian responses are temporary in nature and often transition to recovery or development, decisions to close in developmental aid tend to be more reliant on donor cycles, with larger country-level exits linked to political motivations (Lee 2017). Overall, there are important lessons that can be drawn from the literature on project closure in the development sector (Ahmed et al. 2018), while being attentive to what is distinctive about humanitarian action.

As well as clarifying which ethical considerations are more often discussed, our review also draws attention to several areas that receive less attention. Aside from Maxwell (1999) and Gerstenhaber (2014), the humanitarian principles of neutrality, impartiality, and independence were rarely discussed in relation to project closure (Gerstenhaber 2014; Maxwell 1999). Given their central importance for ethics of humanitarian action (Pringle and Hunt 2015), they are topics that warrant further clarification regarding the role they ought to play in project closure. With few exceptions (Abu-Sada 2012b; Anderson et al. 2012; Orach and De Brouwere 2005), there were also few texts that reported first-hand accounts of how members of local communities and partnering organizations experienced project closures. Further research to better understand project closure from these perspectives is needed, including in-depth case studies of ongoing and completed project closures.

In considering how humanitarian organizations can respond to the ethical considerations identified in this review of the extant literature, we suggest that there are ethical capacities that humanitarian organizations and their staff can seek to develop and which will support ethical project closure. In this context, we understand ethical capacities as the ability and disposition to think and act in ways that are consistent with one's normative commitments. In the light of the findings of the scoping review, we highlight three key ethical capacities that can be developed in relation to closure of humanitarian projects: foresight as a proactive engagement to plan for, anticipate, and tailor closure plans; responsiveness in adapting to dynamic and changing humanitarian contexts with particular concern for the creation or exacerbation of vulnerabilities within populations affected by crisis; and attentiveness to the relational dynamics of closure and the needs, perspectives, and concerns of others including partners, staff, and members of local communities. These capacities help illustrate how humanitarian organizations and their staff can seek to uphold ethical principles such as minimizing harms, fairness, and sustainability, and to enact ethical processes such as providing transparent communication and developing authentic partnerships. See Table 3 for further description of the three capacities.

There is a range of actions that can be undertaken at the organizational level to foster ethical closures and to support those involved. Humanitarian organizations should seek to learn from previous closures in order to improve practices in the future. To do so, mechanisms to evaluate project closures, to document experiences, and to build capacity are needed. These methods should incorporate attention to opportunities and challenges for upholding the ethical considerations identified through this review. Organizations should also develop mechanisms to support national and expatriate staff who are involved in project closure processes, both in terms of psychological support and tangible assistance where the closure of a project means the loss of employment, especially for national staff. This literature review is one component of a research program examining the ethics of closing humanitarian health projects. Findings of the review were a key source for developing a guidance note aiming to spark further reflection and deliberation around humanitarian project closure, and it can be found here: https://humanitarianhealthethics.net/ethicsand-the-closure-of-humanitarian-healthcare-projects/.

\section{Conclusion}

This review has mapped some of the complex ethical terrain of humanitarian project closure, drawing attention to key ethical considerations discussed in the literature. It points to the importance of attending to the ethics of project closure by humanitarian organizations

Table 3 Ethical capacities

\begin{tabular}{ll}
\hline Ethical capacities & \\
\hline Foresight & Foresight entails an active engagement to identify \\
& possible outcomes, anticipate contingencies, and be \\
& diligent in planning (Kurasawa 2007; Moynier 1875). \\
& Robust and ongoing planning is a necessary condition \\
& of ethical project closures, including modelling different \\
& closure scenarios and anticipating how they might \\
& unfold. It also involves learning from previous closure \\
& experiences. \\
& Attentiveness entails openness to and recognition of \\
& the needs and concerns of others who are involved in \\
& or affected by a project closure. It requires critical \\
& self-awareness and engaging with the "social fabric of \\
& action" by "taking stock of relationships, background \\
& expectations, and the ways in which critical response \\
& would come across" in closing projects (Springer 2013). \\
& All project contexts are distinctive and dynamic. \\
& Responsiveness entails orienting and re-orienting \\
& oneself to anomalies, challenges, and changes, \\
& especially in relation to vulnerability. It requires "a \\
temporally continuous thread of attention" \\
(Springer 2013) to local context and flexibility and \\
creativity to adapt closure in consequence.
\end{tabular}


and their partners, and to opportunities to expand knowledge at the intersection of ethics and project closure by further research and through greater dialogue and critical reflection on this topic. The stakes are significant. Poorly planned and managed closures can result in a range of negative consequences, such as disappointment and frustration, ruptures of service or support, divisions within communities and in partnerships, heightened insecurity or inequality, and reputational damage. Our findings may help inform humanitarian actors of ethical considerations in closing projects, and opportunities to uphold and strengthen these aspects of their programming. Ultimately, the findings provide a distinctive angle of view for better understanding the links between project closures, ethical commitments of humanitarians, and conceptions of humanitarian effectiveness.

\section{Abbreviation}

NGO: Non-governmental organization

\section{Acknowledgements}

We are grateful to the humanitarian experts who provided us with documents related to humanitarian project closure. We thank our project partner, Médecins du Monde/ Doctors of the World_-Canada for their support of this project, and all the participants who attended our project feedback meeting on May 24, 2019, in Montreal, Canada.

\section{Authors' contributions}

$L E, J P, R C$, and $M H$ were involved with the conception of the project. NP, $L E$, $J P, R C$, and $M H$ were involved in the design of the project. NP was involved with acquisition of data. NP, LE, S-RH, JP, RC, and MH were involved with the analysis of data and drafting of the manuscript. All authors read and approved the final manuscript.

\section{Funding}

This research was supported by a grant from the Québec Population Health Research Network (QPHRN). Matthew Hunt is supported by a Research Scholar Award from the Fonds de Recherche du Québec-Santé

\section{Availability of data and materials}

The full list of articles included in the scoping review is available at https:// humanitarianhealthethics.net/ethics-and-the-closure-of-humanitarianhealthcare-projects/.

\section{Competing interests}

The authors declare that they have no competing interests.

\begin{abstract}
Author details
'School of Physical and Occupational Therapy, McGill University, Montreal, Canada. ${ }^{2}$ Departments of Philosophy, and Health Administration and Policy, George Mason University, Fairfax, USA. ${ }^{3}$ Medical Consultant at the Public Health Office of the CIUSSS de la Capitale-Nationale, Quebec City, Canada. ${ }^{4}$ Department of Preventive and Social Medicine, Laval University, Quebec City, Canada. ${ }^{5}$ Médecins du Monde, Montreal, Canada. ${ }^{6}$ Ingram School of Nursing, McGill University, Montreal, Canada. ${ }^{7}$ Department of Philosophy, Université de Montréal, Montreal, Canada. ${ }^{8}$ Centre for Interdisciplinary Research in Rehabilitation, 3654 Sir-William-Osler Boulevard, Montreal, QC H3G 1Y5, Canada.
\end{abstract}

Received: 20 June 2019 Accepted: 9 October 2019

Published online: 04 November 2019

\section{References}

Abramowitz S (2015) What happens when MSF leaves? Humanitarian departure and medical sovereignty in postconflict Liberia. In: Abramowitz S, Panter-
Brick C (eds) Medical Humanitarianism: Ethnographies of Practice. University of Pennsylvania Press, Philadelphia, pp 137-154

Abu-Sada C (2012a) Dilemmas, challenges, and ethics of humanitarian action: reflections on Médecins Sans Frontières' perception project. McGill-Queen's University Press, Montreal

Abu-Sada C (2012b) In the eyes of others: how people in crises perceive humanitarian aid. Médecins Sans Frontières. Retrieved from https://www.msf. org/sites/msforg/files/msf-in-the-eyes-of-others.pdf. Accessed 15 Jan 2019

Ahmed F, Dillan H, Robinson J (2018) Planning for succes from start to exit: a review of literature, policy and practice. Retrieved from https:/www. peacedirect.org/us/wp-content/uploads/sites/2/2018/09/Planning-for-successFINAL.pdf. Accessed 15 Jan 2019

Aitken P, Leggat P, Robertson A, Harley H, Speare R, Leclercq M (2009) Health and safety aspects of deployment of Australian disaster medical assistance team members: results of a national survey. Travel Med Infect Dis 7(5):284-290

Akbarzada S, Mackey TK (2018) The Syrian public health and humanitarian crisis: a 'displacement'in global governance? Global Public Health 13(7):914-930

All In Diary (2011) A practical tool for field based humanitarian workers. Retrieved from http://themimu.info/sites/themimu.info/files/documents/Guidelines APracticalToolforFieldBasedHumanitarianWorkers_All\%20In\%20Diary_2011. pdf. Accessed 15 Jan 2019

ALNAP (2018) The state of the humanitarian system. Retrieved from https://sohs. alnap.org/system/files/content/resource/files/main/SOHS\%200nline\%2 OBook\%201\%20updated.pdf. Accessed 15 Jan 2019

Alonso A, Brugha R (2006) Rehabilitating the health system after conflict in East Timor: a shift from NGO to government leadership. Health Policy Plan 21(3):206-216

Alpert R (2010) Contained change: international non-governmental organizations come to Syria in the wake of the Iraqi refugee crisis. Geo Wash Int'l L Rev 42:57

Anderson MB, Brown D, Jean I (2012) Time to listen: hearing people on the receiving end of international aid. CDA Collaborative Learning Projects, Cambridge

Arksey H, O'Malley L (2005) Scoping studies: towards a methodological framework. Int J Soc Res Methodol 8(1):19-32

Ashley J, Jayousi N (2006) Setting a Palestinian national food security strategy. Palest Isr J Polit Econ Cult Retrieved from https://evaluation.msf.org/sites/ evaluation/files/handover_toolkit.pdf. Accessed 15 Jan 2019

Barnett M (2003) What is the future of humanitarianism. Glob Gov 9:401

British Red Cross (2015) British Red Cross in Haiti: a case study on key factors required for a successful programme exit. Retrieved from https://www. chsalliance.org/files/files/Resources/Case-Studies/BRC-Haiti-exit-programmecase-study.pdf. Accessed 15 Jan 2019

British Red Cross (n.d.) Exit strategy guidance. Retrieved from http://www. livelihoodscentre.org/documents/20720/25507/EN_Exit_strategy.docx/06d4 c410-ca29-4902-82ab-cd530ed23342. Accessed 15 Jan 2019

Ford N, Bedell R (2002) Justice and MSF operational choices. Médecins Sans Frontières Retrieved from Accessed 15 Jan 2019

Fuller L (2006) Justified commitments? Considering resource allocation and fairness in Medécins Sans Frontières-Holland. Dev World Bioeth 6(2):59-70

Gardner A, Greenblott K, Joubert E (2005) What we know about exit strategies. Practical guidance for developing exit strategies in the field. Retrieved from https:/reliefweb.int/sites/reliefweb.int/files/resources/A02C7B78FB2B4 08B852570AB006EC7BA-What\%20We\%20Know\%20About\%20Exit\%2 OStrategies\%20-\%20Sept\%202005.pdf. Accessed 15 Jan 2019

Gerstenhaber R (2014) Handover Toolkit 2.0 "success is also measured by what you leave behind". Médecins Sans Frontières Retrieved from https://evaluation.msf.org/sites/evaluation/files/handover_toolkit.pdf. Accessed 15 Jan 2019

Global CCCM Cluster (2014) Camp closure guidelines. Retrieved from http://www. globalcccmcluster.org/system/files/publications/Camp_Closure_Guidelines. pdf. Accessed 15 Jan 2019

Harroff-Tavel M (2010) Violence and humanitarian action in urban areas: new challenges, new approaches. Int Rev Red Cross 92(878):329-350

Heyse L (2016) Choosing the lesser evil: understanding decision making in humanitarian aid NGOs. Routledge, London

Hunt M, Miao J (2018) Moral entanglement and the ethics of closing humanitarian projects. In: Ahmad A, Smith J (eds) Humanitarian action and ethics. Zed Books, London, pp S47-S48

Hurst SA, Mezger N, Mauron A (2009) Allocating resources in humanitarian medicine. Public Health Ethics 2(1):88-89 
ICRC (2004) ICRC assistance policy: adopted by the assembly of the International Committee of the Red Cross on 29 April 2004. Int Rev Red Cross 86(855): 677-693. https://doi.org/10.1017/\$1560775500181106

ICRC (2009) International Committee of the Red Cross: prevention policy: (adopted by the assembly of the ICRC on 18 September 2008). Int Rev Red Cross 91(874):415-430 doi:https://doi.org/10.1017/S1816383109990233

ICRC (2014) The International Committee of the Red Cross's (ICRC's) role in situations of violence below the threshold of armed conflict: policy document, February 2014. Int Rev Red Cross 96(893):275-304. https://doi.org/ $10.1017 /$ S1816383114000113

IFRC (2016) Exit strategy guidance. Retrieved from https://media.ifrc.org/ifrc/wpcontent/uploads/sites/5/2017/01/TOOL-16-Exit-strategy-guidance.docx. Accessed 15 Jan 2019

Inter-Agency Standing Committee (2003) Exit strategy for humanitarian actors in the context of complex emergencies. Retrieved from https:// interagencystandingcommittee.org/system/files/legacy_files/exit_strategy_ for_humanitarian_actors_in_the_context_of_complex_emergencies.pdf. Accessed 15 Jan 2019

Inter-Agency Standing Committee (2014) Guidance note on inter-cluster early recovery. Retrieved from https://www.humanitarianresponse.info/sites/www. humanitarianresponse.info/files/documents/files/Guidance\%20Note\%20on\%2 Ointer-cluster\%20ER\%20draft\%20June\%2024\%202014\%20\%28no\%20Annex\%2 9.pdf. Accessed 15 Jan 2019

Kurasawa F (2007) The work of global justice: human rights as practices. Cambridge University Press, United States of America

Leaning J, Spiegel P, Crisp J (2011) Public health equity in refugee situations. Confl Heal 5(1):6

Lee H (2017) Exit strategy for aid programs: planning exit before entering. Int'l J Soc Sci Stud 5:22

Lee SY, Ozerdem A (2015) Exit strategies. In: Ginty RM, Peterson JH (eds) The Routledge companion to humanitarian action. Routledge, New York, pp 372-384

Lucchi $E$ (2012) Moving from the 'why' to the 'how': reflections on humanitarian response in urban settings. Disasters 36:S87-S104

Maxwell D (1999) Programmes in chronically vulnerable areas: challenges and lessons learned. Disasters 23(4):373-384

McGoldrick C (2011) The future of humanitarian action: an ICRC perspective. Int Rev Red Cross 93(884):965-991

Médecins du Monde (2015) MdM Health Project Planning Guide 2015. Retrieved from https://issuu.com/medecinsdumonde/docs/mdm_health_project_ planning_guide_2. Accessed 15 Jan 2019

Moher D, Liberati A, Tetzlaff J, Altman DG (2009) Preferred Reporting Items for Systematic Reviews and Meta-Analyses: the PRISMA statement. Ann Intern Med 151(4):264-269

Moynier G (1875) Ce que c'est que la Croix rouge. Bulletin international des Sociétés de la Croix Rouge 6(21):1-8

O'Mathúna D (2016) Ideal and nonideal moral theory for disaster bioethics. Hum Aff 26(1):8-17

OCHA (2018) Global humanitarian overview. Retrieved from https://www.unocha. org/sites/unocha/files/GHO2018.pdf. Accessed 15 Jan 2019

Orach CG, De Brouwere V (2005) Integrating refugee and host health services in West Nile districts, Uganda. Health Policy Plan 21(1):53-64

Patrick S (2000) The check is in the mail: improving the delivery and coordination of postconflict assistance. Glob Gov 6:61

Pringle J, Hunt M (2015) Humanitarian action. In: ten Have H (ed) Encyclopedia of global bioethics. Springer International Publishing, Cham, pp 1562-1570. https://doi.org/10.1007/978-3-319-05544-2_235-1

Redfield P (2013) Life in crisis: the ethical journey of doctors without borders. University of California Press, Berkeley, Los Angeles, London

Rieff D (1995) The humanitarian trap. World Policy J 12(4):1-11

Rubenstein J (2015) Between Samaritans and states: the political ethics of humanitarian INGOs. Oxford University Press, Oxford

Seo H-N, Pettigrew L (2011) An interview with Médecins Sans Frontières. Br J Gen Pract 61(592):e761-e762. https://doi.org/10.3399/bjgp11X606753

Slim H (2015) Humanitarian ethics: a guide to the morality of aid in war and disaster. Oxford University Press, Oxford

Solidarités International (2016) Solidarités International Operational Framework. Retrieved from https://www.solidarites.org/wp-content/ uploads/2017/05/Solidarit\%C3\%A9s-International-operational-framework. pdf. Accessed 15 jan 2019
Sphere Association (2018) The sphere handbook: humanitarian charter and minimum standards in humanitarian response. Retrieved from https:// spherestandards.org/wp-content/uploads/Sphere-Handbook-2018-EN.pdf. Accessed 15 Jan 2019

Springer E (2013) Communicating moral concern: an ethics of critical responsiveness. MIT Press, Cambridge

Trócaire (2016) Humanitarian handbook. Retrieved from https://www.trocaire.org/ sites/default/files/resources/policy/humanitarian-handbook-english_0.pdf. Accessed 15 Jan 2019

UNDP (2012) UNDP and early recovery. Retrieved from https://www.undp.org/ content/dam/undp/library/crisis\%20prevention/20121101_UNDP_early_ recovery.pdf. Accessed 15 Jan 2019

World Food Programme (2004) Programme options for transition from emergency response. Retrieved from https://m.wfp.org/sites/default/files/ Exiting\%20Emergencies\%20-\%20\%282005\%29.pdf. Accessed 15 Jan 2019

World Health Organization (n.d.) Chapter 11 Phasing out. In: Managing WHO humanitarian response in the field. Retrieved from https://www.who.int/ hac/techguidance/tools/manuals/who_field_handbook/11/en/. Accessed 15 Jan 2019

\section{Publisher's Note}

Springer Nature remains neutral with regard to jurisdictional claims in published maps and institutional affiliations.

\section{Submit your manuscript to a SpringerOpen ${ }^{\circ}$ journal and benefit from:}

- Convenient online submission

- Rigorous peer review

- Open access: articles freely available online

High visibility within the field

- Retaining the copyright to your article

Submit your next manuscript at $>$ springeropen.com 